\title{
POHJOISMAINEN ELOKUVA KUKOISTAA
}

Ruben Östlundin ohjaama The Square (2017) voitti parhaan elokuvan palkinnon tämän kevään Cannesin elokuvajuhlilla. Aki Kaurismäki sai puolestaan parhaan ohjaajan palkinnon helmikuussa järjestetyillä Berliinin elokuvafestivaaleilla. Sekä Östlund että Kaurismäki jatkavat minimalistisen pohjoismaisen auteur-elokuvan perinnettä Carl Theodor Dreyerin ja Ingmar Bergmanin viitoittamalla tiellä. Maineikkaat kansainväliset festivaalipalkinnot ovat osoituksia alueen elokuvan arvostuksesta. Buumiksi puhjennut pohjoismaiseen elokuvaan kohdistuva kiinnostus ei kuitenkaan rajoitu tunnettuihin ohjaajiin vaan koskee myös populaareja genrejä. Esimerkiksi Taneli Mustosen kauhuelokuva Bodom (2016) kiinnostaa yleisöjä kauhuelokuvia esittävillä festivaaleilla, vaikka se ei olekaan kerännyt mainitun kaltaisia palkintoja. Ja erityisesti norjalainen kauhu on genre-elokuvayleisöjen suosiossa. Nordic noiriksi brändätyt rikoselokuvat ja -televisiosarjat puolestaan tavoittavat miljoonia katsojia. Maailmassa on vain neljä maata, joihin ei ole myyty nordic noirin prototyypiksi mielletyn Sillan (Bron/Broen, 2011-) esitysoikeuksia. Teosten arvostus ja suosio ovat laajemminkin kasvattaneet pohjoismaihin kohdistuvaa kiinnostusta: englannin kielellä on julkaistu koko joukko hyggeä (tanskalaista mukavuutta) käsitteleviä elämäntapaoppaita - kuten myös villapaitojen neulontaohjeita. Viimeksi mainituille on löytynyt kysyntää siitä saakka, kun Rikoksen (Forbrydelse, 2007) päähenkilö Sara Lund ryhtyi ratkomaan Nana Birk Larsenin murhaa pehmeässä ja lämpimässä vaatteessa. Jopa suomalaisista kalsarikänneistä tuli maailmanlaajuinen netti-ilmiö, joka noteerattiin muotilehti Voguessa (Luckel 2017).

Kansainväliset festivaalit sekä niiltä saadut tunnustukset ovat lisänneet kiinnostusta pohjoismaiseen elokuvaan. Kun katsojat ovat nähneet hyvän pohjoismaisen elokuvan, he ovat saattaneet ryhtyä katsomaan myös muita pohjoismaisia elokuvia - sekä uusia että vanhoja. Menestyksessä ei kuitenkaan ole kyse yksin elokuvien korkeasta tasosta, sillä niin pohjoismainen muotoilu, laadukas koulutus, alhainen korruptio kuin puhdas luontokin ovat kasvattaneet alueeseen kohdistuvaa mielenkiintoa jo monen vuoden ajan. Esimerkiksi Ison-Britannian kohdalla pohjoismaisen elokuvan buumia on selitetty helposti ylitettävällä erolla (Stougaard-Nielsen 2016). Brittien perspektiivistä katsottuna Pohjolan elokuvat ovat eksoottisia, mutta eksoottisuus ei ole vierasta toiseutta vaan pikemminkin erilaista länsimaalaisuutta kiinnostavassa 
ympäristössä. Elokuvat tarjoavat mahdollisuuden niin pohjoismaiseen elämäntapaan kuin kaupunkeihin ja luontoonkin tutustumiselle. Ilmiön nurjana puolena voi pitää sitä, että viiden eri pohjoismaan kulttuurit eivät näyttäydy yksilöllisinä, vaan ne sekoittuvat vastaanotossa yleiseksi pohjoismaalaisuudeksi, jota ei ole olemassa: on esimerkiksi luultavaa, että briteistä islantilaiset villapaidat ja suomalaiset jussipaidat ovat yleispohjoismaisia villapaitoja vailla sen kummempia kulttuurisia erityispiirteitä. Yksi esimerkki pohjoismaisen elokuvan kiinnostuksesta pohjoismaiden ulkopuolella on joka syksyinen Lyypekin pohjoismaisen elokuvan festivaali, Nordische Filmtage Lübeck, joka järjestetään tänä vuonna jo 59. kerran. Festivaalissa elokuva kuin elokuva kiinnostaa katsojia niin, että salit ovat näytöksissä täynnä. Kiinnostuksen kasvamisessa ja menestyksessä sokaistumisen vaaraa ei kuitenkaan pitäisi olla, sillä edelleen suuri osa pohjoismaisesta elokuvasta on kotimarkkinoille tuotettuna sellaista, joka tuskin kiinnostaa kansainvälisiä katsojia. Vuodelta 2016 tällaisia suomalaisen elokuvan esimerkkejä ovat vaikka Lauri Nurksen komedia Nuotin vierestä, Alli Haapasalon kirjailijoiden myrskyisää rakkautta kuvaava Syysprinssi sekä aiheen kansainvälisestä potentiaalisuudesta huolimatta Aleksi Mäkelän Love Records - Anna mulle Lovee.

Pohjoismaisen elokuvan menestys ja suosio ruokkivat akateemisen maailman kiinnostusta, sillä ilmiön kulttuurinen merkitys on huomattava. Kansainväliset yliopistot ovat jo pitkään tarjonneet pohjoismaista elokuvaa käsitteleviä kursseja, mutta niiden rinnalle ovat ilmaantuneet myös pohjoismaista elokuvaa käsittelevät konferenssit, seminaarit ja symposiumit. Selvimmin buumi näkyy akateemisessa kustannustoiminnassa. Vielä vähän reilu kymmenen vuotta sitten pohjoismaista elokuvaa käsitteleviä artikkeleita saattoi olla vaikea saada julkaistuksi isoilla kansainvälisillä tiedekustantajilla. Nyt tilanne on toinen. Muutoksen lähtölaukauksena voi pitää Andrew Nestingenin ja Trevor G. Elkingtonin toimittamaa artikkelikokoelmaa Transnational Cinema in a Global North: Nordic Cinema in Transition, joka ilmestyi vuonna 2005 Wayne State University Pressin kustantamana.

Viime vuosina teosten julkaisutahti on kiihtynyt. Vuonna 2015 Edinburgh University Press julkaisi Tommy Gustafssonin ja Pietari Käävän toimittaman artikkelikokoelman Nordic Genre Film: Small Nation Film Cultures in the Global Marketplace. Kokoelma keskittyy nimensä mukaisesti pohjoismaiseen genreelokuvaan, joka on liian usein jäänyt taide-elokuvan ja tunnettujen tekijöiden varjoon. Seuraavana vuonna kirjamarkkinoille ilmestyi Wiley-Blackwellin kustantamana, Mette Hjortin ja Ursula Lindqvistin toimittama artikkelikokoelma A Companion to Nordic Cinema. Suurikokoinen teos käsittelee niin pohjoismaisten elokuvien tuottamista, levittämistä kuin esittämistäkin läpi maiden elokuvahistorian. Ensi vuonna kirjat saavat jatkoa, kun Arne Lunden ja Anna Stenportin toimittama Cinemas of Elsewhere: A Globalized History of Nordic Film Cultures julkaistaan. Artikkelikokoelma paneutuu pohjoismaisten elokuvien ja elokuvantekijöidenkin asemaan ja rooliin maailman elokuvakulttuureissa. Toki pohjoismaista elokuvaa käsitteleviä artikkelikokoelmia on julkaistu aikaisemminkin, esimerkiksi vuonna 1999 ilmestyi John Libbeyn kustantamana John Fullertonin ja Jan Olssonin toimittama Nordic Explorations: Film Before 1930, mutta nyt määrät ovat selvästi kasvussa. Uutta on sekin, että teoksia julkaisevat arvostetut kansainväliset tiedekustantajat. Intellectin kustantamaa Journal of Scandinavian Cinema -aikakauskirjaakin on ilmestynyt jo kunnioitettavat seitsemäntoista numeroa. 
Pohjoismainen nykyelokuva kytkeytyy monin tavoin aikansa elokuvallisiin, kulttuurisiin ja yhteiskunnallisiin virtauksiin ja muutoksiin, mikä käy hyvin ilmi edellä mainituista teoksista. Niin tekee myös tämän numeron kansi, josta meitä katsoo Raisa (Rosa Söderholm) elokuvasta He ovat paenneet (J. P. Valkeapää, 2014). Raisa asuu lastenkodissa, jonne asepalvelustaan suorittamassa ollut ja luvatta lomalle karannut Joni (Teppo Manner) lähetetään suorittamaan siviilipalvelusta. Vaikka nuorilla on lastenkodissa eri status, he ovat molemmat yhteiskunnan marginaaliin sulkemia ongelmatapauksia. Kun Joni saapuu lastenkotiin, paikan johtaja ohjeistaa häntä: "Sun pitää ymmärtää semmonen asia, et nää nuoret ei oo täällä omasta vapaasta tahdostaan. Tää on niinku yhteiskunnan tapa pitää huolta, et ne ei oo tuolla ympäriinsä, et niil on kaikki hyvin." Repliikki kertoo yksilöiden hyväksi naamioidusta, vallitsevaa normaaliutta ylläpitävästä sääntelystä, sekä vallitsevan järjestyksen tavasta syrjään sysäämisellä uhata niitä, jotka eivät kykene toimimaan tai halua toimia sen normaaliksi määrittämällä tavalla. Kommentti on omiaan kyseenalaistamaan perinteistä käsitystä pohjoismaisesta hyvinvointiyhteiskunnasta. Samaa tematiikkaa on monissa nordic noireissa.

Lastenkodin johtajan repliikki muistuttaa Paul Verhaeghen $(2014,153)$ toteamusta, jonka mukaan silloin, kun nuoret eivät täytä heihin asetettuja odotuksia, yhteiskunta joko tuomitsee heidät normienrikkojiksi tai leimaa epänormaaleiksi. Kun vallitsevaan normaaliuteen sopimattomia, kuten Raisa ja Joni, suljetaan ytimen ulkopuolelle, siirrytään aktiiviseen, yhteiskunnalliseen ihmisjätehuoltoon. Henry A. Girouxin $(2012 ; 2009)$ mukaan ihmisjätehuolto on markkinavetoisen uusliberalismin perustaa, jossa nöyryytetään ja rankaistaan niitä, jotka eivät toimi taloudellisesti tuottavalla tavalla. Raisa ja Joni pakenevat yhdessä yhteiskunnan heille määräämästä "vankeudesta" maantielle, joka assosioituu vapauteen. Teos saa kuitenkin painajaismaisen käänteen, kun Raisa ja Joni yöpyvät saaressa vieraassa mökissä. Maastoasuiset miehet ottavat nuoret vangeiksi. Heitä kidutetaan ja nöyryytetään sekä kahleissa että häkeissä. Hieman nordic noirien tyyliin pelottava kuvasto on väreistä huuhdottua ja monet otokset ovat pienimuotoisia ja painostavan pitkiä. Vielä rikoselokuvia selvemmin jakso kytkeytyy pohjoismaisten kauhuelokuvien tematiikkaan, sillä genren teoksissa on jo usean vuoden ajan kyseenalaistettu pohjoismaisten ihmisten luontosuhdetta. Nyt luonto näyttäytyy vaarallisena ja väkivaltaa uhkuvana paikkana, joka olisi paras kiertää kaukaa (Iversen 2016). Elokuvalla on kaikkien kauhujensa jälkeen utooppinen, miltei satumainen loppu, mikä on sopivaa sikäli, että elokuva on Grimmin Hannu ja Kerttu -sadun mukaelma. Ulos rajaamisen kannalta sekä yksilö että nuoria jahtaava yhteiskunta voittavat, sillä vaikka nuoret eivät enää ole yhteiskunnan kontrollissa, josta he karkaavat elokuvassa useita kertoja, he ovat kuitenkin periferiassa, jossa he eivät enää vallitsevaa järjestystä häiritse.

Numeron artikkelit ovat kaikki omissa kehyksissään kytköksissä normaaliuteen: Kate Moffatilla saamelainen elokuva tuotannolliseen ja eksoottiseen kuvaamiseen, Anna Pitkämäellä väkivallan ja seksuaalisuuden toisiinsa kytkemisen konventionaaliseen esittämiseen ja Tuukka Hämäläisellä stereotyyppien ylläpitämään "normaaliuteen" ja sen murtamiseen.

Numeron avaavassa artikkelissa Kate Moffat tarkastelee saamelaisten representaatioissa tapahtuneita muutoksia ja analysoi saamelaisten mediaorganisaatioiden toimintaa. Aihe on ajankohtainen. Akateemisessa maailmassa saamelaiseen elokuvaan on kiinnitetty viime vuosina kasvavissa määrin huomiota. Yksi indikaattori on Scott MacKenzien ja Anna Westerstahl 
Stenportin toimittama Films on Ice: Cinemas of the Arctic-artikkelikokoelma, jonka Edinbugh University Press julkaisi muutama vuosi sitten. Moffat vie keskustelua eteenpäin määrittelemällä ja analysoimalla saamelaisen elokuvan verkostoitumiskäytännön tapoja, joita ovat tekninen yhteistyö, koulutukseen ja valmennukseen perustuva verkostoituminen sekä levityksen avulla elokuvafestivaaleilla tapahtuva vaihto. Uusien käytäntöjen myötä elokuvien ja muiden mediasisältöjen tuottajilla on aikaisempaa enemmän valtaa sekä omien sisältöjensä että niiden levityksen ja esityksen saralla. Moffatista vielä ei ole kuitenkaan selvää, miten saamelaiset mediainstituutiot voisivat parhaiten edustaa saamelaisväestöä niin napapiirin alueella kuin sen ulkopuolellakin.

Moffatin artikkelissa saamelaisen elämäntavan esittäminen eksoottisena tai siitä vapaana on merkittävä juonne. Voimallisemmin esittämisen tapaan keskittyvät numeron kaksi muuta artikkelia. Anna Pitkämäki analysoi artikkelissaan sukupuolen ja seksuaalisuuden kytkeytymistä väkivallan esittämiseen suomalaisissa Vares- ja ruotsalaisissa Wallender-elokuvissa. Elokuvia tarkastellaan Teresa de Lauretisin määrittämänä sosiaaliteknologiana, jonka mukaan elokuva voi yhtä hyvin sekä ylläpitää että haastaa väkivallan esittämisen sukupuolistuneisuutta. Oleellista on se, että elokuvan nähdään tarjoavan katsojalle tilan "kuvatteluun" ja asioiden välisten suhteiden merkityksellistämiseen. Tästä näkökulmasta Pitkämäki analysoi sekä miesten että naisten rooleja väkivallan tekijöinä ja uhreina, usein näkymättömäksi jäävää lähisuhdeväkivaltaa sekä erityisiä tapoja, joilla väkivallan ja seksuaalisuuden suhde tehdään elokuvissa näkyväksi. Yhdeksän Vares- ja kolmentoista Wallender-elokuvan väkivaltaa sisältävien kohtausten tarkastelu suhteessa rikoselokuvan konventioihin ja yhteiskuntaan osoittaa yhtäläisyyksiä sarjojen välillä mutta myös selviä, erityisesti väkivallan seurausten ja yhteiskuntakritiikin esittämiseen liittyviä eroja.

Esittämistä pohtii myös Tuukka Hämäläinen, joka tarkastelee tutkijan representaation muutosta norjalaisessa katastrofielokuvassa The Wave (2015). Ensimmäisen pohjoismaisen katastrofielokuvan esittämän tutkijan representaatiota verrataan sekä aiempiin tutkijakuvausta kirjallisuudessa ja elokuvissa tarkastelleisiin tutkimuksiin että Hollywoodissa tuotettujen katastrofigenren elokuvien - erityisesti Twister (1996) ja Dante's Peak (1997) - tutkijarepresentaatioihin. The Wave osoittaa muutosta realistisempaan ja positiivisempaan tutkijan esittämiseen laimentamalla ja hylkäämällä stereotyyppisyyttä ja genren konventioita, kuten ajatuksen tiedemiehen "hulluudesta" ja romanttisen sivujuonen pakollisuudesta. Muutosta pohtiessaan Hämäläinen kysyy, onko The Wave osa laajempaa tutkijakuvan muutosta vai onko poikkeavan tutkijarepresentaation syynä ennemminkin vain se, että elokuva on tehty Hollywoodin ulkopuolella. Jälkimmäisessä tapauksessa muutos voisi kytkeytyä erityisesti pohjoismaisuuteen.

Pohjoismaissa näytelmäelokuvien aiheet eivät monestikaan ole kunnioittaneet kansallisia rajoja, sillä aiheita on kierrätetty monin erilaisin tavoin. Tämän osoittaa kiinnostavalla tavalla Kimmo Laine elokuvia Varastettu kuolema (Nyrki Tapiovaara, 1938) ja Elämä panoksena (Alf Sjöberg, Med livet som insats, 1940) tarkastelevassa katsauksessaan. Molemmat elokuvat perustuvat suomenruotsalaisen Runar Schildtin novelliin "Köttkvarnen" ("Lihamylly"), joka julkaistiin vuonna 1919. Laine nostaa esille sekä yhtäläisyyksiä että eroavaisuuksia analysoidessaan elokuvien tuotantotaustaa ja tulkintoja Schildtin novellista. Katsaus on osoitus siitä, kuinka adaptaatiotutkimus ja pohjoismaisen elokuvan tutkimus kytkeytyvät hedelmällisellä tavalla toisiinsa. 
Tämän Lähikuvan kirjoittajien tekstit korostavat niin pohjoismaisen nykyelokuvan rikkautta kuin pohjoismaisen elokuvan käsitteen hyödyllisyyttäkin. Toivomme numeron rohkaisevan alueen elokuvaa koskeviin keskusteluihin ja pohdintoihin.

Salossa ja Espoossa kesälomien kynnyksellä 2017

Tommi Römpötti ja Jaakko Seppälä

\section{Kirjallisuus}

Giroux, Henry A. (2012) Disposable Youth, Racialized Memories, and the Culture of Cruelty. New York \& London: Routledge.

Giroux, Henry A. (2009) Youth in a Suspect Society: Democracy or Disposability? New York: Palgrave Macmillan.

Iversen, Gunnar (2016) “Between Art and Genre: New Nordic Horror Cinema”. Teoksessa Mette Hjort \& Ursula Lindqvist (toim.), A Companion to Nordic Cinema. Malden et al.: WileyBlackwell, 332-350.

Luckel, Madeleine (2017) “There's a Finnish Concept for Drinking at Home Alone in Your Underwear, but Vogue Was Always on It". Vogue. <http://www.vogue.com/article/finnish-trendkalsarikannit-vogue-archive> (linkki tarkistettu 27.6.2017).

Stougaard-Nielsen, Jakob (2016) “Nordic Noir in the UK: The Allure of Accessible Difference”. Journal of Aesthetics and Culture, vol. 8:1, 32704, DOI: 10.3402/jac.v8.32704.

Verhaeghe, Paul (2014) What about Me? The Struggle for Identity in a Market-Based Society. Melbourne \& London: Scribe. 